\title{
Tensile Strength of GFRP Reinforcing Bars with Hollow Section
}

\author{
Young-Jun You, Ki-Tae Park, Dong-Woo Seo, and Ji-Hyun Hwang \\ Structural Engineering Research Institute, Korea Institute of Civil Engineering and Building Technology, 283 Goyangdae-Ro, \\ Ilsanseo-Gu, Goyang-Si, Gyeonggi-Do 411-712, Republic of Korea \\ Correspondence should be addressed to Young-Jun You; yjyou@kict.re.kr
}

Received 24 November 2014; Revised 14 January 2015; Accepted 15 January 2015

Academic Editor: Antônio G. de Lima

Copyright (C) 2015 Young-Jun You et al. This is an open access article distributed under the Creative Commons Attribution License, which permits unrestricted use, distribution, and reproduction in any medium, provided the original work is properly cited.

Fiber reinforced polymer (FRP) has been proposed to replace steel as a reinforcing bar (rebar) due to its high tensile strength and noncorrosive material properties. One obstacle in using FRP rebars is high price. Generally FRP is more expensive than conventional steel rebar. There are mainly two ways to reduce the cost. For example, one is making the price of each composition cost of FRP rebar (e.g., fibers, resin, etc.) lower than steel rebar. Another is making an optimized design for cross section and reducing the material cost. The former approach is not easy because the steel price is very low in comparison with component materials of FRP. For the latter approach, the cost could be cut down by reducing the material cost. Therefore, an idea of making hollow section over the cross section of FRP rebar was proposed in this study by optimizing the cross section design with acceptable tensile performance in comparison with steel rebar. In this study, glass reinforced polymer (GFRP) rebars with hollow section and $19 \mathrm{~mm}$ of outer diameter were manufactured and tested to evaluate the tensile performance in accordance with the hollowness ratio. From the test results, it was observed that the tensile strength decreased almost linearly with increase of hollowness ratio and the elastic modulus decreased nonlinearly.

\section{Introduction}

Galvanized reinforcement has been started to be used in the concrete bridge design after the 1960s due to corrosion problems. However, the electrolysis between the zinc-based coating and steel raised various problems, including damage of the corrosion protective film of the galvanized steel reinforcing bar (rebar), and resulted in its abandonment. In the early 1970s, the Federal Highway Administration in the USA undertook a research on 50 types of reinforcing steel coating, which introduced the epoxy-coated steel rebar that is still being used today [1]. However, severe corrosion problems were reported for the epoxy-coated steel embedded concrete [2] without proposal of any solution enabling solving this corrosion problem at the root.

Since the corrosion of steel rebar is not a structural problem but is basically a material problem, a feasible solution would be to use reinforcement made of noncorrosive material even if several noncorrosive reinforcements, such as stainless rebars, were fabricated. Researches to develop a rebar using fiber reinforced polymer (FRP) were initiated in the 1960s and resulted in its exploitation as structural member [1]. FRP is composed of resin and epoxy by fiber and resin and is featured by outstanding properties including noncorrosiveness, high specific strength, fatigue resistance, low specific weight, nonmagnetism, and nonconductivity. Owing to these features, FRP can be utilized in marine structures, such as piers and floating structures, or concrete structures exposed to calcium chloride, or when nonmagnetic or nonconductive properties are necessary [3].

USA, Canada, and Europe engaged the active research on FRP, of which several achievements were actually applied in construction sites (Figure 1). In Korea, the Korea Institute of Civil Engineering and Building Technology (KICT) developed a reinforcing bar made of glass fiber reinforced polymer (GFRP) exhibiting a shape similar to the reinforcing steel in Figure 2. However, FRP rebar remains still poorly adopted in the construction of structures with very few applications as a main member. Despite its numerous advantages, the reasons for the timid use of the FRP rebar as structural member are its high cost compared to the traditional reinforcing steel, its low modulus of elasticity, and the occurrence of brittle failure unlike steel which exhibits plastic behavior. 


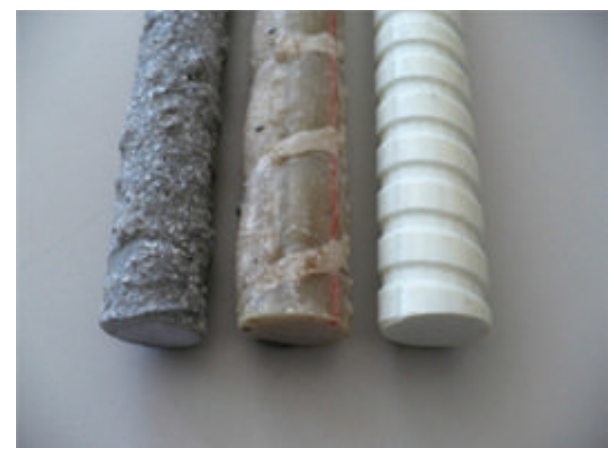

Figure 1: Pultrall V-rod, Aslan 100, and Schőck ComBAR (left to right) $[20]$.

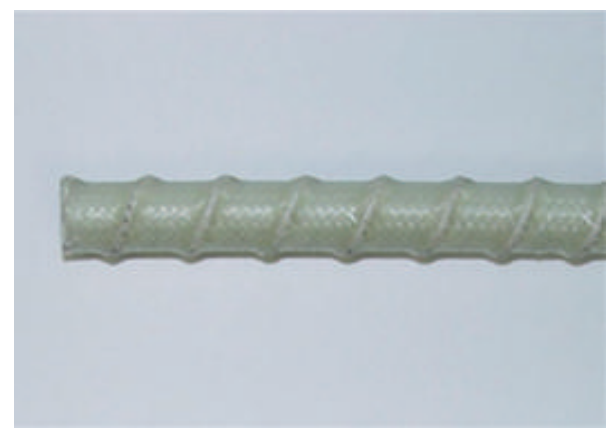

FIGURE 2: GFRP rebar of KICT [17].

In the case of a circular reinforcement made of FRP, the tensile strength generally tends to reduce with increasing diameter. This phenomenon can be explained by the fact that the stress developed at the fiber located near the surface of the reinforcement is not fully transferred to the fibers located at the center.

Accordingly, this study evaluates the stability of the GFRP rebar with hollow section developed in a will to reduce its fabrication cost and having an acceptable tensile performance. Tensile test is conducted on 5 sets of specimens with diameter of $19 \mathrm{~mm}$ and fabricated for 5 different hollowness ratios. Based upon the test results, the change in the tensile properties of the GFRP rebar is examined with respect to the hollowness ratio and the tensile performance so as to propose an efficient sectional hollowness ratio. Bonding performance is also an importance factor for FRP rebar because the surface of FRP rebar has not been standardized and has various shapes (e.g., Figure 1) [4, 5]. This project is an ongoing research and preliminary results are reported in this paper. Bonding performance is currently under investigation by the authors.

\section{Research Backgrounds}

Unlike steel, FRP experiences brittle failure and its elastic modulus reaches about a quarter to steel in the case of glass fiber. Such drawbacks can be overcome by using fibers which have higher tensile performance. Jones and DiBenedetto [6] conducted experiments on composites made of carbon/ carbon, glass/glass, aramid/carbon, and glass/carbon fibers
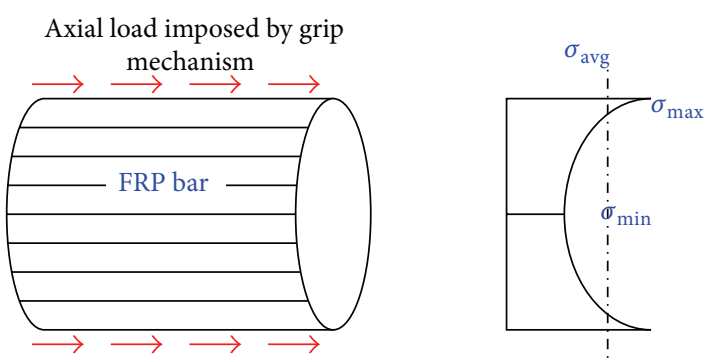

Distribution of normal stresses

FIGURE 3: Shear lag.

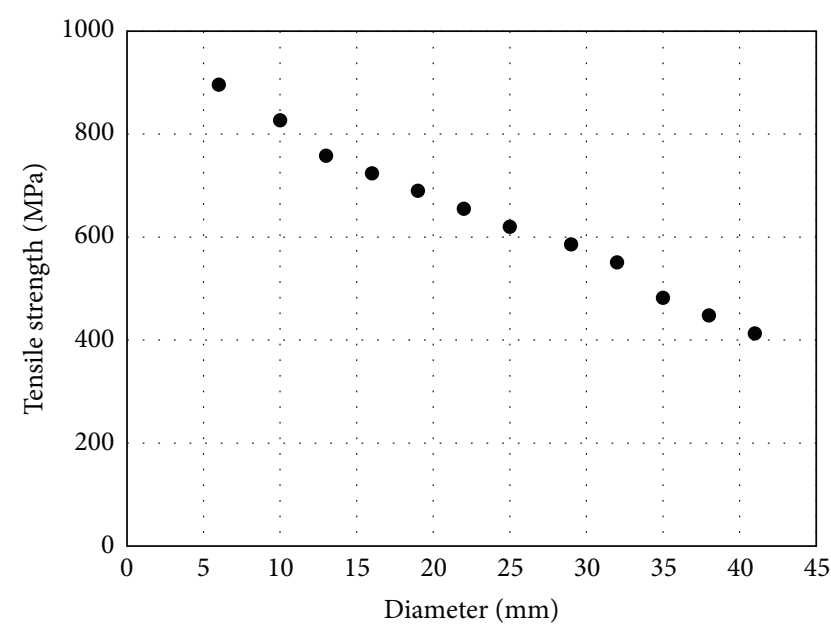

FIGURE 4: Change of tensile strength with diameter [11].

and concluded that pseudoductile behavior could be secured by an even distribution of small quantities of fibers with small elongation. However, securing such behavior is accompanied with a higher production cost since fiber exhibiting higher performance has a higher price $[7,8]$.

The tensile properties of the FRP rebar depend on the content, size of fiber, and the gripping system. Unlike steel reinforcement, the tensile strength of the FRP rebar is a function of diameter. In particular, when the tensile force is applied through a steel grip (later shown in Figure 8), the tensile strength of FRP bar undergoes change with a larger diameter caused by the development of higher stress in the outer fibers than in the inner ones due to the shear lag occurring in the section of the rebar as shown in Figure 3. With this reason, the increment of the diameter of the rebar to deal with this shear lag results in the nonefficiency of the section and loss of strength $[9,10]$. Figure 4 verifies the loss of the tensile strength according to the increment of diameter of a commercialized GFRP rebar [11].

Since the shear lag impedes the central fibers from fully developing their proper performance, a cost-efficient section can be designed by removing these central fibers from the cross section. In the case of FRP bar, shown in Figure 2 with a $19 \mathrm{~mm}$ diameter, the sum of the material and labor costs can be estimated as approximately $\$ 2.84 / \mathrm{m}$. For example, the total 


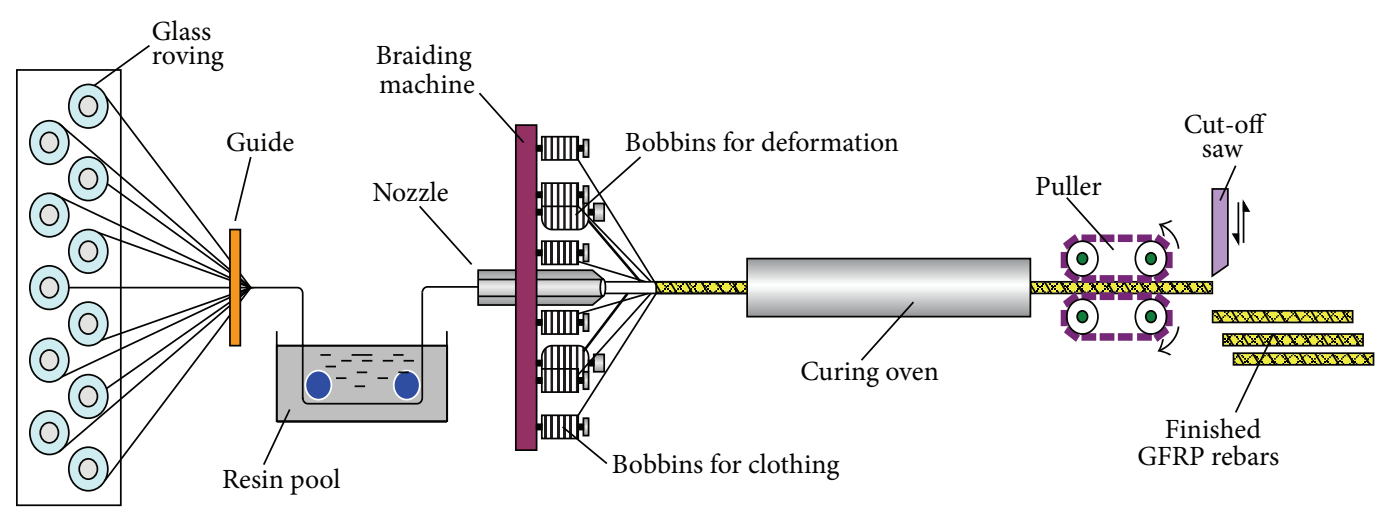

FIGURE 5: Modified braidtrusion process.

TABLE 1: Material properties of GFRP rebar.

\begin{tabular}{lccc}
\hline Material & Model & $\begin{array}{c}\text { Tensile strength } \\
(\mathrm{MPa})\end{array}$ & $\begin{array}{c}\text { Elastic modulus } \\
(\mathrm{MPa})\end{array}$ \\
\hline Resin 1 & HETRON-922 & 86 & 3,170 \\
Resin 2 & DION-9100 & 79 & 3,216 \\
Fiber 1 & SE1200 & 2,600 & 81,000 \\
Fiber 2 & Nylon & 70 & 75,000 \\
\hline
\end{tabular}

manufacturing cost and the material cost could be reduced by $12 \%$ and $20 \%$, respectively, with having a $20 \%$ hollow section.

\section{Performance Evaluation for Hollow GFRP Rebar}

3.1. Materials. The GFRP rebar was fabricated by mixing Eglass fiber (Fiber 1 in Table 1) and unsaturated polyester resins that are DION-9100 and HETRON-922. Polyamide-based nylon fiber (Fiber 2 in Table 1) was used for the formation of the protuberance at the surface of the deformed rebar in order to secure mechanical bonding with concrete. The properties of the adopted materials are explained in Table 1.

3.2. Fabrication Method of GFRP Rebar. The typical methods applied to the manufacture of FRP are the pultrusion, the braiding, and the filament winding. Pultrusion is a continuous manufacturing process producing unidirectional members with constant cross section and is known as the most economic and rapid method for the production of prestress tendons and reinforcing bars, which makes it the most adopted method for the manufacture of FRP rebar $[12,13]$.

The bond performance with concrete constitutes the utmost performance required for the FRP member to fulfill its role inside concrete. Even if the pultrusion offers the advantage of continuously producing members with constant cross section, an additional process is necessary to achieve the bond performance with concrete since the so-produced member exhibits a smooth surface [14]. In a will to solve this problem, Ko et al. [15] proposed a process combining both pultrusion and braiding. This process called braidtrusion additionally executes braiding during the pultrusion process so as to form a netlike skin at the surface of the reinforced fiber bundle. The braidtrusion bears thus the continuous manufacturing and the preservation of a constant cross section featured by the pultrusion together with the rough surface or skin featured by the braiding. However, the braidtruded FRP rebar experiences loss of its tensile performance due to the voids generated in the section by the air entrained during the resin impregnation of the relatively loose fiber bundles constituting the core of the rebar [16].

In order to reduce the voids inside the section, KICT [17] proposed an improved braidtrusion process as shown in Figure 5. While preserving the advantages of the previous braidtrusion, this modified process improves the tensile performance through the reduction of the voids and the enhancement of the fiber arrangement by introducing a definite prestress into the reinforced fiber bundles and the string for protuberance to secure bond performance with concrete. The GFRP rebar specimens of this study were manufactured using this process.

3.3. Manufacture of Hollow GFRP Rebar. Five types of specimens were planned to observe the change in the tensile properties of the GFRP rebar according to the hollowness ratio over the cross section. A reference specimen was fabricated first to compare the change in the tensile characteristics according to the hollowness ratio in the section by manufacturing a GFRP rebar without an inserted tube. All other specimens were inserted with a polyurethane tube with 4 different diameters (e.g., 6, 8, 10, and $12 \mathrm{~mm}$ ). The dimensions and characteristics of the specimens are listed in Table 2 and Figure 6. In Table 2, the section hollowness ratio was calculated with the outer diameter of inserted polyurethane tube because it is expected that its material property will contribute insignificantly to the tensile strength of the specimen.

In the designation of the specimens in Table 2, D19 indicates the diameter of the GFRP rebar and HD stands for diameter of the hollow tube. For example, D19HD8 indicates the GFRP rebar with overall sectional diameter of $19 \mathrm{~mm}$ and outer diameter of $8 \mathrm{~mm}$ for the inserted hollow tube. In Table 2, the inner diameter of the rebar corresponds to the value measured in the portion without protuberance and the outer diameter includes the protuberance. 
TABLE 2: Dimensions and characteristics of test specimens.

\begin{tabular}{lccccc}
\hline \multirow{2}{*}{$\begin{array}{c}\text { Specimen } \\
\text { Designation }\end{array}$} & \multicolumn{2}{c}{ Diameter $(\mathrm{mm})$} & Section hollowness ratio & Number of rovings \\
\hline D19HD0 & 3 & Inner & Outer & $0 \%$ & 217 \\
D19HD6 & 6 & 18.58 & 20.87 & $10.4 \%$ & 196 \\
D19HD8 & 6 & 18.63 & 20.97 & $18.3 \%$ & 180 \\
D19HD10 & 6 & 18.68 & 20.83 & $28.4 \%$ & 159 \\
D19HD12 & 6 & 18.75 & 20.78 & $39.7 \%$ & 133 \\
\hline
\end{tabular}

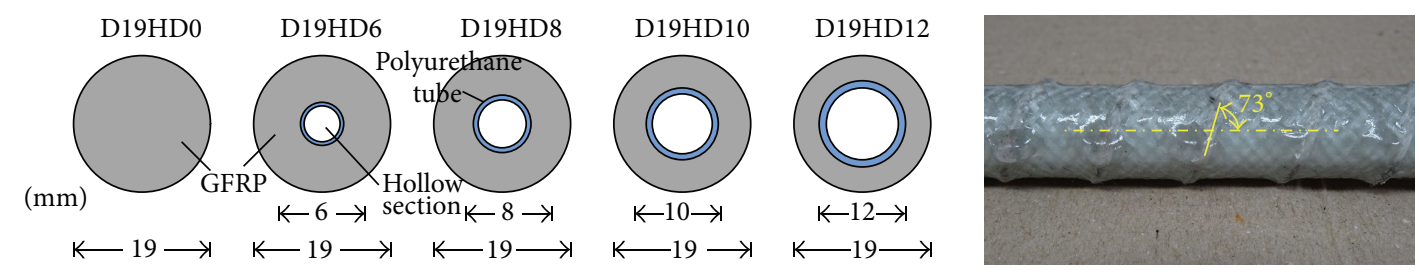

FIGURE 6: Specification of test specimens.

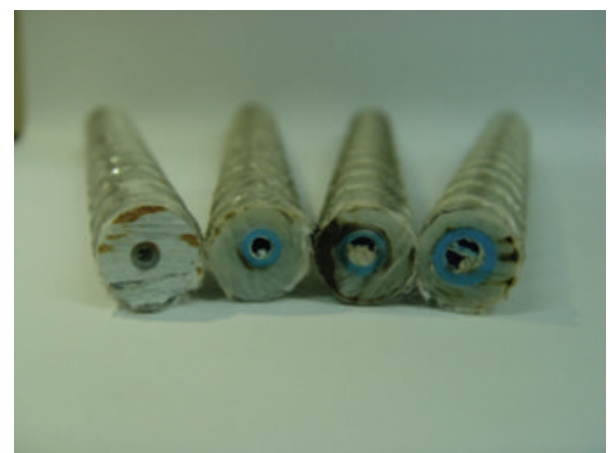

Figure 7: Cross section of test specimens.

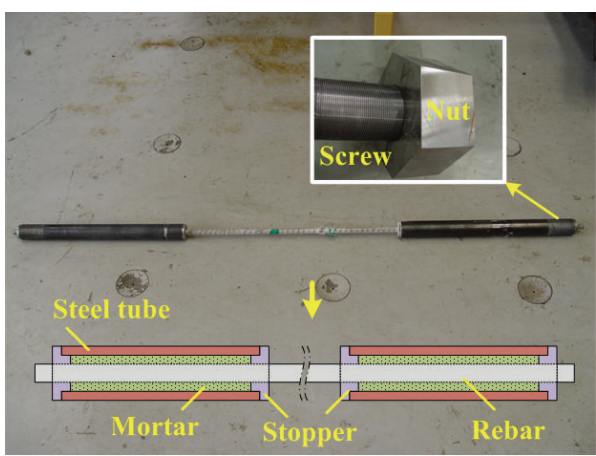

FIGURE 8: Gripping system.
A polyurethane tube was used to form the hollow section of the GFRP rebar. Figure 7 depicts the cross section of the completed GFRP bars with hollow section.

3.4. Test Method. After being completed the GFRP bars were cut to a definite length, and the grips for tensile test were fabricated using cylindrical steel tubes with thickness of $7.1 \mathrm{~mm}$ and length of $1000 \mathrm{~mm}$. Two stoppers with a hole perforated at their center were disposed at both ends of each steel tube so as to insert and position the rebar at the center of the steel tube. As shown in Figure 8, one side grip was formed beforehand at another side of the rebar. The space between the rebar and the steel tube was then filled with nonshrinkage mortar and curing was conducted during 7 maintaining the verticality of the rebar. Thereafter, the grip was formed at the opposite end of the rebar following the same method.

A screw was disposed at one end of the cylindrical steel tube constituting the grip so as to fix the specimen with a nut. A specimen has two nuts at both end sides of the steel tube and testing machine pulls these nuts.
The specimen was installed on a universal testing machine (UTM) with capacity of $1,000 \mathrm{kN}$ prior to attaching an electrical resistance strain gage at the center of the specimen. Loading was applied through displacement control at speed of $2 \mathrm{~mm} / \mathrm{min}$. The load and corresponding strains were collected using a data logger.

\section{Test Results}

4.1. Mechanical Characteristics of Tensile Performance. Table 3 and Figure 9 show a sample of test results and show the relationship between the tensile stress calculated from an applied force divided by cross section area and strain measured at the center of the rebar. All specimens showed a typical failure mechanism of FRP material that the curve between stress and strain increases linearly up to peak load and fails suddenly. The maximum tensile load and elastic modulus are seen to vary according to the hollowness ratio with an overall tendency to decrease with larger hollowness ratio. Table 3 arranges the peak tensile load and elastic modulus measured in each type of specimens. In Table 3, 
TABLE 3: Tensile test results.

\begin{tabular}{|c|c|c|c|c|c|c|}
\hline \multirow{2}{*}{ Specimen } & \multicolumn{3}{|c|}{ Tensile strength $(\mathrm{MPa})$} & \multicolumn{3}{|c|}{ Elastic modulus (MPa) } \\
\hline & Measured & Mean (S.D.) & Ratio & Measured & Mean (S.D.) & Ratio \\
\hline \multirow{3}{*}{ D19HD0 } & 1,218 & & & 53,520 & \multirow{3}{*}{$55,073(1,502)$} & \multirow{3}{*}{$100 \%$} \\
\hline & 1,229 & $1,193(54)$ & $100 \%$ & 55,180 & & \\
\hline & 1,131 & & & 56,519 & & \\
\hline \multirow{6}{*}{ D19HD6 } & 1,016 & \multirow{6}{*}{$1,091(55)$} & \multirow{6}{*}{$91.4 \%$} & 59,276 & \multirow{6}{*}{$56,917(1,464)$} & \multirow{6}{*}{$103.3 \%$} \\
\hline & 1,147 & & & 55,623 & & \\
\hline & 1,106 & & & 56,681 & & \\
\hline & 1,131 & & & 57,229 & & \\
\hline & 1,029 & & & 55,190 & & \\
\hline & 1,117 & & & 57,505 & & \\
\hline \multirow{6}{*}{ D19HD8 } & - & \multirow{6}{*}{$877(26)$} & \multirow{6}{*}{$73.5 \%$} & - & \multirow{6}{*}{$51,439(2,163)$} & \multirow{6}{*}{$93.4 \%$} \\
\hline & 863 & & & 52,641 & & \\
\hline & 898 & & & 49,577 & & \\
\hline & 873 & & & 50,036 & & \\
\hline & 908 & & & 50,267 & & \\
\hline & 843 & & & 54,674 & & \\
\hline \multirow{6}{*}{ D19HD10 } & 746 & \multirow{6}{*}{$736(9)$} & \multirow{6}{*}{$61.7 \%$} & 49,664 & \multirow{6}{*}{$46,252(2,003)$} & \multirow{6}{*}{$84.0 \%$} \\
\hline & 741 & & & 45,073 & & \\
\hline & - & & & - & & \\
\hline & 722 & & & 46,453 & & \\
\hline & 736 & & & 44,988 & & \\
\hline & 738 & & & 45,080 & & \\
\hline \multirow{6}{*}{ D19HD12 } & 684 & \multirow{6}{*}{$686(37)$} & \multirow{6}{*}{$57.5 \%$} & 38,819 & \multirow{6}{*}{$35,439(2,233)$} & \multirow{6}{*}{$64.3 \%$} \\
\hline & 731 & & & 35,442 & & \\
\hline & 640 & & & 34,792 & & \\
\hline & 730 & & & 33,410 & & \\
\hline & 666 & & & 37,175 & & \\
\hline & 667 & & & 32,999 & & \\
\hline
\end{tabular}

S.D.: standard deviation.

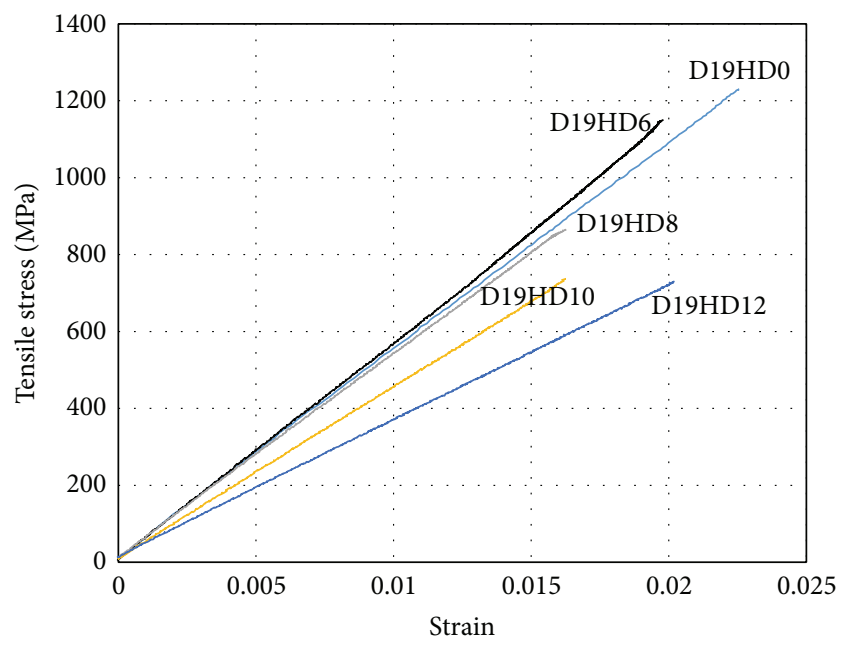

FIgURE 9: Stress-strain curve sample of GFRP rebar specimens.

ratio means the changed value over that of the rebar without having a hollow section.
4.2. Change of Tensile Characteristics. The change in the tensile characteristics of the hollow GFRP rebar according to ratio of hollow area is examined using the results of Table 3. Since the average tensile strength in Table 3 , as the value obtained by dividing the maximum load by the whole area of the rebar, tends to decrease with a larger ratio of hollow area, regression analysis was performed to examine this relationship and the results are plotted in Figure 10. For the conditions of the regression analysis, the hollow area ratio of 0 indicates satisfaction of the performance of the GFRP rebar without hollowness and the hollow area ratio of $100 \%$ corresponds to the zero tensile strength. As shown in Figure 10, it may safely be said that the tensile strength of the GFRP rebar tends to reduce almost linearly with the increase of the ratio of hollow area. Even though the coefficient of determination of the fitting curve with second order is closer to $100 \%$ than that of the first degree and the coefficient of determination becomes $100 \%$ when the fitting curve of the fourth degree is applied, considering the difference of those two is not so big in this test with just six specimens and referring to Figure 4 for commercialized products, it would be reasonable to consider that the tensile strength decreases with increasing the hollowness ratio. 


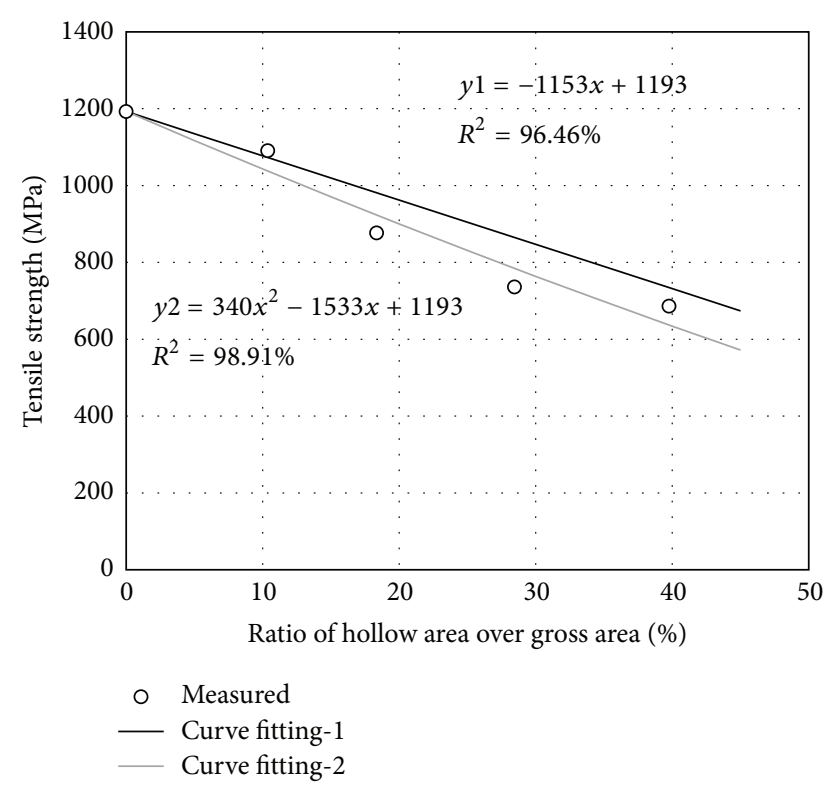

FIGURE 10: Tensile strength for hollow section ratio.

In general, the average axial tensile strength of the fiber composite can be obtained by the rule of mixtures as expressed in [18]

$$
\begin{aligned}
& \sigma_{\mathrm{FRP}}=\sigma_{f} V_{f}+\sigma_{m} V_{m}, \\
& E_{\mathrm{FRP}}=E_{f} V_{f}+E_{m} V_{m},
\end{aligned}
$$

where $\sigma_{\mathrm{FRP}}, \sigma_{f}$, and $\sigma_{m}$ are the average tensile strengths of the composite, fiber, and resin, respectively, $V_{f}$ and $V_{m}$ are the respective volumetric ratios of the fiber and resin, and $E_{\mathrm{FRP}}$, $E_{f}$, and $E_{m}$ are the elastic moduli of the composite, fiber, and resin, respectively.

If we assume that there is no void in the composite section, $V_{f}+V_{m}=1$. When the tensile strength of the GFRP rebar is calculated using the rule of mixtures, the tensile strength of the resin is often neglected since it is significantly smaller than that of the glass fiber. Accordingly, the tensile strength of the FRP rebar becomes proportional to the quantity of fiber.

The exact volume fraction of fiber cannot be provided since burn-out test was not executed on the specimens in this study. However, the relative volume fraction of fiber can be deduced by comparing the used number of rovings listed in Table 2. The number of rovings used in the manufacture of the 4 types of hollow GFRP rebar reaches, respectively, $90 \%, 83 \%$, $73 \%$, and $61 \%$ over the number of rovings for manufacturing the plain GFRP rebar and is practically similar to the tensile strength change ratio. Consequently, the tensile strength of the rebar is proportional to the quantity of fiber.

Figure 11 presents the change in the elastic modulus according to the hollow area ratio. The elastic modulus decreases, in the main, as hollowness increases. Even though D19HD6 shows higher elastic modulus than that of D19HD0, this may be considered as experimental deviation. Unlike the reduction of the tensile strength, it can be seen that this

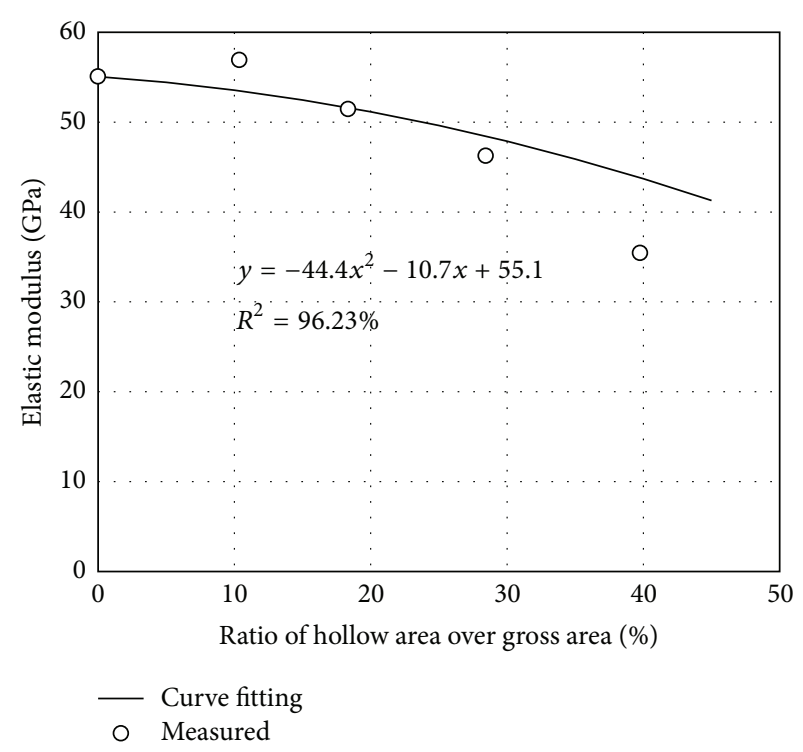

FIGURE 11: Elastic modulus for hollow section ratio.

change is nonlinear. The results of the regression analysis show a second-order reduction of the elastic modulus. Even though the fitting curve with third order agrees more accurately with test results, this curve shows the elastic modulus of rebar with hollow section increases until $12 \%$ of hollowness and this might be unreasonable. Equations (1a) and (1b) express also the proportionality of the elastic modulus with the volume of fiber in FRP. However, the rule of mixtures was derived assuming linear elastic behavior and uniform and isotropic material characteristics of the resin and fiber in the absence of void inside FRP without theoretical formula expressed in function of the material characteristics [19]. Therefore, the application of the rule of mixtures on the test results in this study appears also unreasonable.

4.3. Optimal Design of Hollow GFRP Rebar. Optimization seems necessary since the tensile strength and elastic modulus show different variation according to the increase of the hollow section ratio. With regard to the manufacture of the GFRP rebar, various objective functions can be considered, such as the tensile strength or the production cost of the rebar. This objective function should thus be adequately selected with respect to the circumstances. In this study, the quantity of fiber is chosen as an objective function and the optimization intends to find the hollow area ratio for which the performance is optimized according to the production cost.

Figure 12 concurrently plots the reduction ratios of the tensile strength, fiber quantity, and elastic modulus obtained by regression analysis. Since the tensile strength exhibits a reduction ratio identical to that of the fiber quantity, the optimal hollow area ratio can be found by comparing the reduction ratios of the fiber quantity and elastic modulus. As shown in Figure 12, the reduction ratio of the elastic modulus is not large when the hollow area ratio is small but experiences sudden decrease when the hollow area ratio reaches a certain level (after approximately 30\%). The condition at which the 


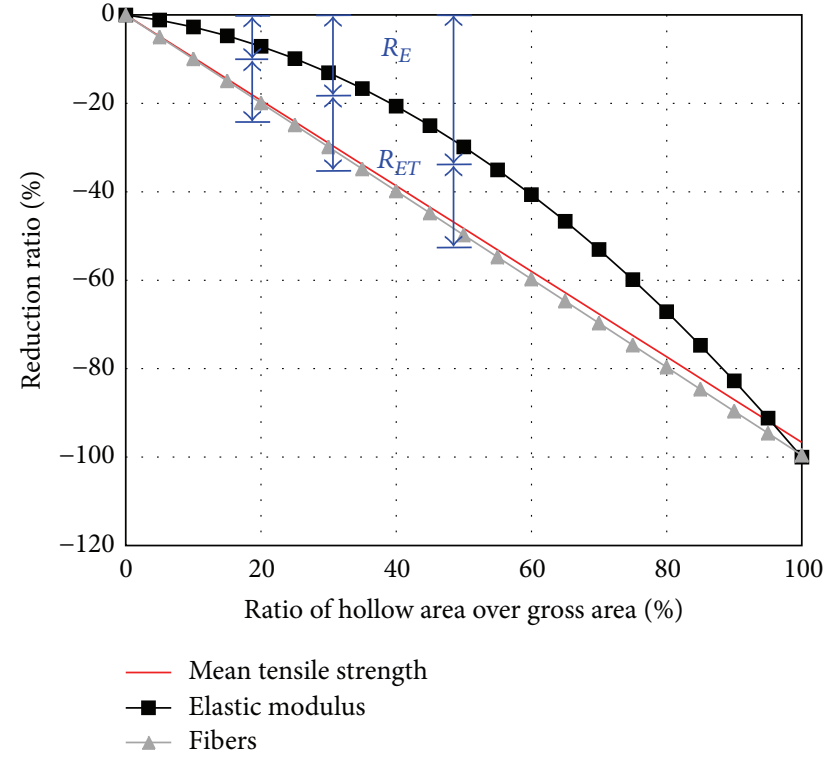

FIGURE 12: Reduction ratio of material properties.

reduction ratio of the elastic modulus becomes equal to the difference between the reduction ratios of the elastic modulus and tensile strength, expressed as $R_{E}$ and $R_{E T}$, respectively, in Figure 12, occurs for a hollow area ratio of $36 \%$. This indicates that even if the tensile strength reduces with larger hollow area ratio, the best reduction of fiber quantity (i.e., optimized unit price) and tensile performance are achieved when the ratio of hollow area is equal to $36 \%$.

\section{Conclusions}

This study intended to improve the efficiency of the performance of GFRP rebar with respect to its production cost by exploiting the characteristic in which the tensile performance of the rebar reduces with larger diameter. The tensile performance was examined considering hollow GFRP rebar with diameter of $19 \mathrm{~mm}$ and the test results were discussed and led to the following conclusions.

(1) The stress-strain behavior of the hollow GFRP rebar was typical of that of FRP material that the curve between stress and strain increases linearly up to maximum load and fails suddenly.

(2) The tensile strength of the hollow GFRP rebar reduced almost linearly with the increase of the ratio of hollow area. However, the elastic modulus reduces nonlinearly.

(3) The optimal (i.e., economical) tensile performance is achieved for a hollow area ratio of $36 \%$ when using the quantity of fiber, that is, the material ratio, as objective function.

\section{Conflict of Interests}

The authors declare that there is no conflict of interests regarding the publication of this paper.

\section{Acknowledgment}

This project was supported by the KICT's basic project named "Harbor Structure's Performance Improvement Technologies Using FRP Composites.”

\section{References}

[1] American Concrete Institute (ACI), ACI 440R-96: State-of-theArt Report on Fiber Reinforced Plastic (FRP) Reinforcement for Concrete Structures, 1996.

[2] R. J. Keesler and R. G. Power, "Corrosion of epoxy coated rebars-keys segmental Bridge-Monroe County," Report No. 888A, Florida Department of Transportation, Materials Office, Corrosion Research Laboratories, Gainesville, Fla, USA, 1998.

[3] Pultrall Inc, Product Guide Specification, Section 03205, Pultrall Inc, 2001, http://www.pultrall.com.

[4] H. Mazaheripour, J. A. O. Barros, J. M. Sena-Cruz, M. Pepe, and E. Martinelli, "Experimental study on bond performance of GFRP bars in self-compacting steel fiber reinforced concrete," Composite Structures, vol. 95, pp. 202-212, 2013.

[5] M. Pepe, H. Mazaheripour, J. Barros, J. Sena-Cruz, and E. Martinelli, "Numerical calibration of bond law for GFRP bars embedded in steel fibre-reinforced self-compacting concrete," Composites Part B: Engineering, vol. 50, pp. 403-412, 2013.

[6] K. D. Jones and A. T. DiBenedetto, "Fiber fracture in hybrid composite systems," Composites Science and Technology, vol. 51, no. 1, pp. 53-62, 1994.

[7] D. W. Seo, B. S. Han, and S. W. Shin, "Behavior according to confinement of compressive concrete on flexural members reinforced with FRP bars," Journal of the Korea Institute for Structural Maintenance and Inspection, vol. 12, no. 3, pp. 110-118, 2008 (Korean).

[8] Y. C. Choi, K. S. Park, H. K. Choi, and C. S. Choi, "Behavior of reinforcement ratio on concrete beams reinforced with lab spliced GFRP bar," Journal of the Korea Institute for Structural Maintenance and Inspection, vol. 15, no. 1, pp. 67-76, 2011 (Korean)

[9] R. Cusson and Y. Xi, "The behavior of fiber-reinforced polymer reinforcement in low temperature environmental climates," Tech. Rep. CDOT-DTD-R-2003-4, Department of Civil, Environmental \& Architectural Engineering, University of Colorado, 2003.

[10] Z. Achillides and K. Pilakoutas, "Bond behavior of fiber reinforced polymer bars under direct pullout conditions," Journal of Composites for Construction, vol. 8, no. 2, pp. 173-181, 2004.

[11] Hughes Brothers, 2014, http://aslanfrp.com/aslan100/Resources/ Aslan100a.pdf.

[12] A. L. Kalamkarov, A. V. Georgiades, D. O. MacDonald, and S. B. Fitzgerald, "Pultruded fibre reinforced polymer reinforcements with embedded fibre optic sensors," Canadian Journal of Civil Engineering, vol. 27, no. 5, pp. 972-984, 2000.

[13] ISIS Canada, Design Manual 3: Reinforcing Concrete Structures with Fiber Reinforced Polymers, The Canadian Network of Centers of Excellence on Intelligent Sensing for Innovative Structures, 2001. 
[14] Z. Wang, Y. Goto, and O. Joh, "Bond strength of various types of fiber reinforced plastic rods," in Proceedings of the 4th International Symposium on Fiber Reinforced Polymer Reinforcement for Reinforced Concrete Structures, W. D. Charles, H. R. Sami, and N. Antonio, Eds., vol. 188, pp. 1117-1130, 1999.

[15] F. K. Ko, W. Somboonsong, and H. G. Harris, "Fiber architecture based design of ductile composite rebars for concrete structures," in Proceedings of the 11th International Conference of Composite Materials, M. L. Scott, Ed., vol. 6, pp. 723-730, Gold Coast, Australia, 1997.

[16] M. S. Ahmadi, M. S. Johari, M. Sadighi, and M. Esfandeh, "An experimental study on mechanical properties of GFRP braidpultruded composite rods," Express Polymer Letters, vol. 3, no. 9, pp. 560-568, 2009.

[17] Korea Institute of Construction Technology (KICT), "Design and construction technology for concrete structures using advanced composite materials (in Korean)," Interim report submitted to the Korea Research Council of Public Science and Technology, Korea, 2006.

[18] I. M. Daniel and O. Ishai, Engineering Mechanics of Composite Materials, Oxford University Press, 1994.

[19] L. C. Bank, Composites for Construction: Structural Design with FRP Materials, John Wiley \& Sons, New York, NY, USA, 2006.

[20] D. T. C. Johnson, Investigation of glass fibre reinforced polymer reinforcing bars as internal reinforcement for concrete structures [M.S. thesis], Department of Civil Engineering, University of Toronto, 2009. 

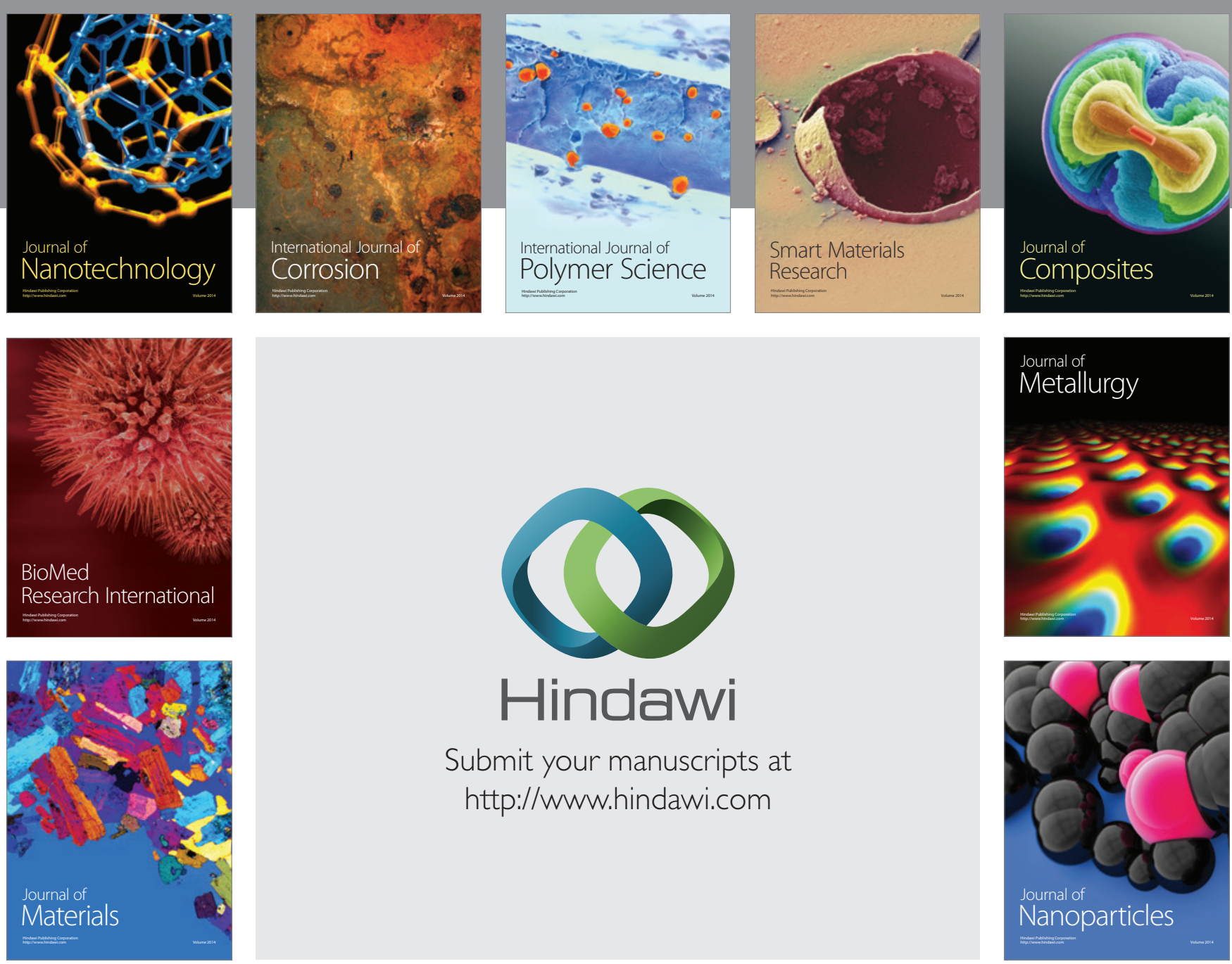

Submit your manuscripts at http://www.hindawi.com
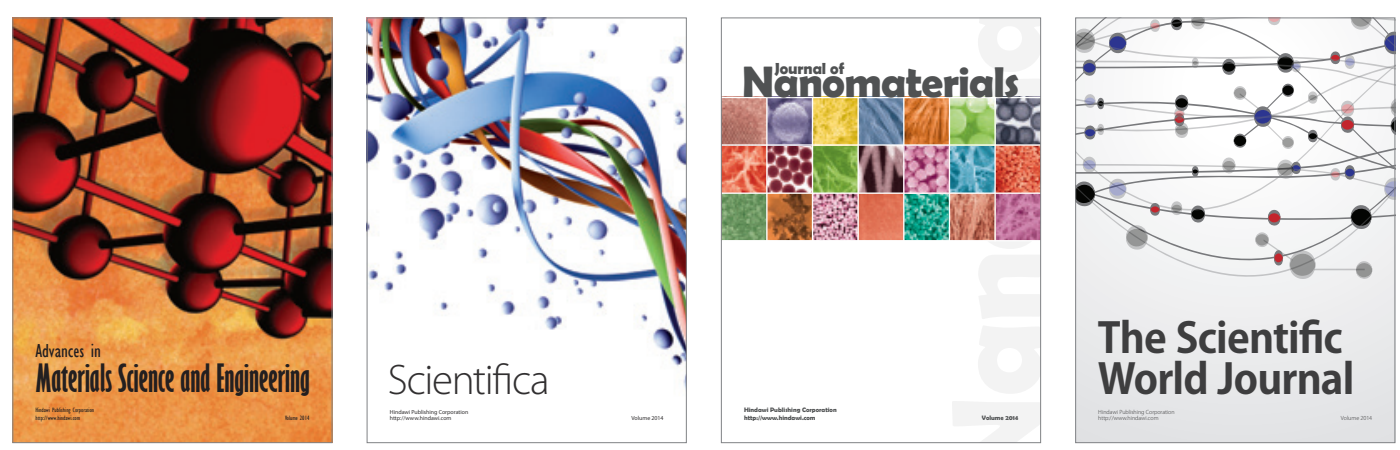

\section{The Scientific World Journal}
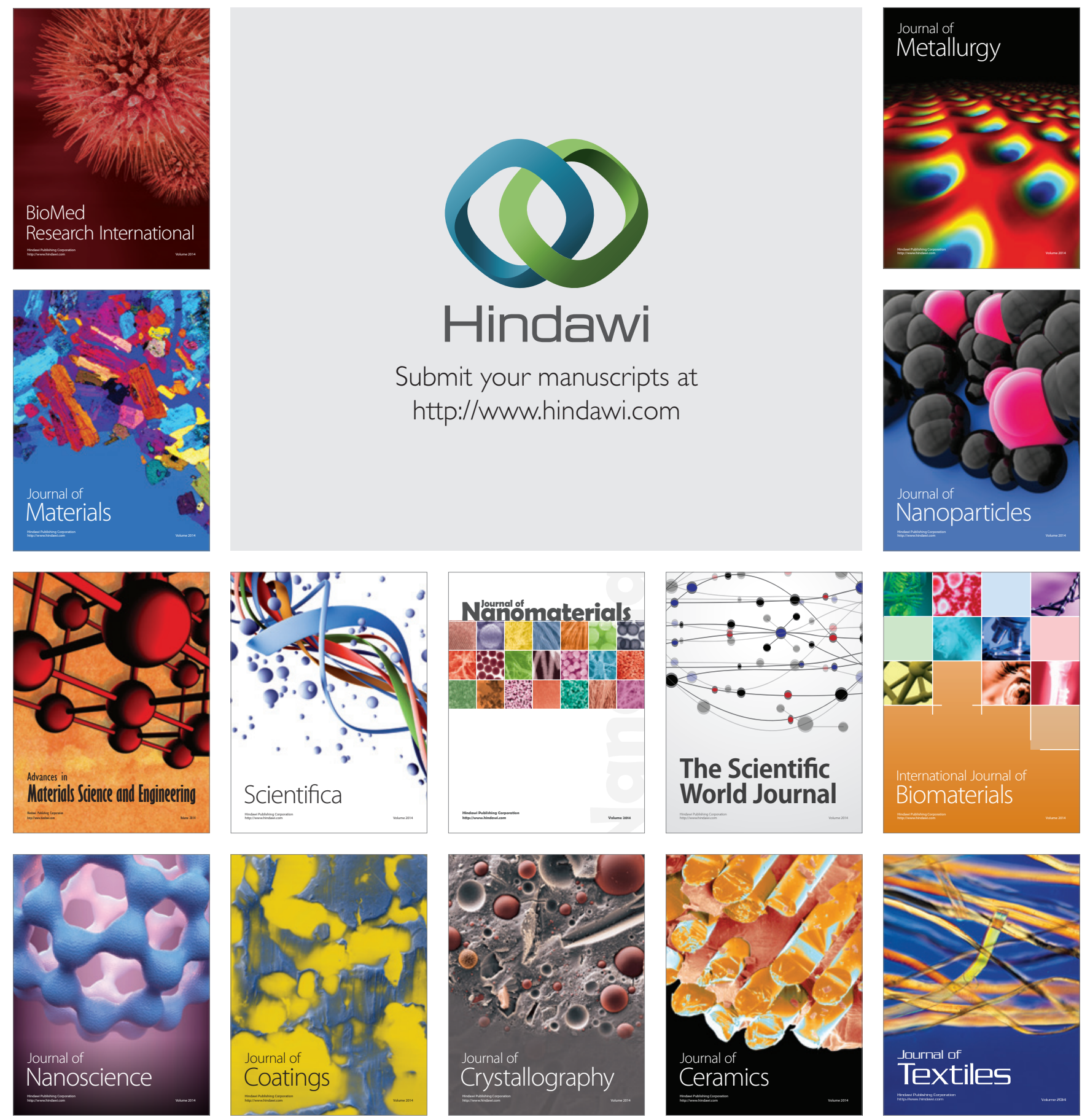